\title{
Pedagogía praxeológica y social : hacia otra educación.
}

\author{
Por Carlos Germán Juliao Vargas. (2014) \\ Bogotá: Corporación Universitaria Minuto de Dios. \\ Uniminuto
}

\author{
Benjamín Barón Velandia ${ }^{1}$ \\ Corporación Universitaria Minuto de Dios - UNIMINUTO \\ Fundación para la Calidad Educativa - FUCAED \\ benjaminbv@gmail.com
}

1 Docente-Investigador de la Facultad de Educación de la Corporación Universitaria Minuto de DiosUNIMINUTO. Vicepresidente de la Fundación para la Calidad Educativa (FUCAED). PhD (C) en Educación de la Universidad Central de Nicaragua. Magíster en Docencia de la Universidad de La Salle. Especialista en Informática y Multimedios de la Fundación Universitaria Los Libertadores y Licenciado en Filosofía y Letras de la Universidad de La Salle. 


\section{Impregnar de nuevos sentidos vitales la educación}

Carlos Germán Juliao Vargas, sacerdote Eudista, consagrado investigador en el campo del Desarrollo Social y Sustentable y gran soñador en el campo la pedagogía y la educación, presenta en su libro compilado "Pedagogía praxeológica y social: hacia otra educación" un paisaje de experiencias, testimonios, y conceptos, en el que más allá de realizar un ejercicio de sistematización a modo de dossier donde reconoce los aportes de maestros e investigadores de diversas facultades de la Corporación Universitaria Minuto de Dios-UNIMINUTO, en el que trasciende los visos de una definición de lo que puede ser una educación y encuentra morada en las pinceladas que desde la filosofía, la teología, la pedagogía infantil, la psicología, el periodismo, la ciencia, entre otras, le brindan para configurar lo que hoy día se constituye como el enfoque educativo de El Minuto de Dios, permitiéndose el abandono de las grandes autopistas de conocimientos y posibilitando las brechas que le generan, en palabras de Morín, es importante aprender a navegar en océanos de incertidumbres, a través de archipiélagos de certezas.

En este paisaje dialógico, Juliao, hace una simbiosis, una amalgama coalescente entre los dos elementos fundamentales de la construcción de lo que hoy día conocemos como la obra El Minuto de Dios, por un lado, la praxeología y por el otro, no como contrario, sino como diferente, la pedagogía social, desde donde surge en una sincronicidad perfecta la categoría sensible de "pedagogía praxeológica y social" que se constituye en el tercero absoluto, en un bucle recursivo, en un proceso interdependiente, donde la sola mirada de la pedagogía praxeológica o de la pedagogía social, como independientes no alcanza la comprensión holística de la obra que nos presenta Juliao, por el contrario, hay que superar esa mirada fragmentaria y habitarlas en ese sistema de relaciones en el que se reconocen y se complementan.

Los vórtices que permiten comprender las apuestas de UNIMINUTO, se pueden reconocer en los vestigios que se encuentran en las facultades y programas. No ejemplos, pero si referentes inspiradores que se vislumbran en las escenas actuales, como los podemos ver a continuación en:

Primero "La formación de pedagogos infantiles en Uniminuto: entre la pedagogía praxeológica y la pedagogía social, los retos de una educación inclusiva" Luz Esperanza Bustos Sierra, Martha Cecilia Molina Penagos y Hugo Eduardo Caraballo Cadena, docentes investigadores del programa de Licenciatura Pedagogía Infantil, replantean y tensionan el tema de la responsabilidad adquirida por parte de las instituciones que se dedican a la formación de formadores y los múltiples retos a los que están enfrentados, por ejemplo, al ineludible desafío de encontrar en el aula estudiantes con diversidades 
Pedagogía praxeológica y social : hacia otra educación. Por Carlos Germán Juliao Vargas. (2014). Bogotá: Corporación Universitaria Minuto de Dios. Uniminuto | Benjamín Barón Velandia |

condiciones de vida y darle respuesta a sus necesidades comunes y especiales con calidad y eficacia, reconociendo las cualidades y competencias en sus procesos de aprendizajes.

Segundo "Educación para el desarrollo en zapatos latinoamericanos: apuestas ético-epistémicas para una educación social y crítica" Israel Arturo Orrego Echeverría, filósofo e investigador del CED, su perspectiva se permiten integrar tres aspectos fundamentales del ser vivo (emocional, sentimental y celebrativo) en pro de las transformaciones de las estructuras cognitivas y de las maneras de relacionamiento pedagógico que favorecen los proyectos sociales en los que la homogeneidad y la estandarización del pensamiento sean replanteados por el rescate de la diversidad, de los otros, de esos que han sido unificados por el pensamiento colonizador y neocolonizador que puede ser superado por lo que en términos de Morín se denominó la religazón, ese re-ligar la realidad que fragmentaron para evitar que la comprendiéramos en su totalidad y por tanto nunca comprendiéramos cómo se construyó el contexto.

Tercero "La pedagogía social como totalidad narrativa: posibilidades críticas formativas" Jair Duque Román, docente investigador en el campo de las ciencias sociales, plantea que en esta experiencia resulta fundamental realizar un acto de "develar" las características del lenguaje que se utiliza en la actualidad, lo que en múltiples escenarios se presenta de manera disciplinar, generando burbujas de protección o de "objetividad" permitiéndose esa distancia desde donde se construye la realidad que habitamos, porque en este horizonte, la realidad es la manera como construimos al otro, a los otros o a lo otro, a través del lenguaje, por medio de esos nuevos significados y significantes. Entendiéndose este lenguaje en términos de Wittgenstein, como el vehículo que articula el conocimiento.

Cuarto "La Escuela de Medios para el Desarrollo: una experiencia praxeológica en un contexto de educación social" Fernando Gutiérrez, docente investigador, periodista y escritor, quien propone que la Escuela de Medios es considerada "punta de lanza de la praxeología en la Facultad de Ciencias de la Comunicación" porque ha generado desde su nacimiento procesos de divulgación en diversos medios de comunicación, trascendiendo lo meramente comunicativo e instalándose en los flujos de relaciones que se establecen en las múltiples reflexiones educativas sobre el uso de los medios de comunicación en los procesos de transformación y reconstrucción del tejido social.

Quinto "Como si fuera un marco teórico" Fabio E. Medellín V. caracterizado como maestro por naturaleza de fotografía, televisión y apreciación cinematográfica en UNIMINUTO, se aventura a la elaboración de sus propias teorías, aprovechando la notable experiencia que le permiten los años y las vivencias, conceptos a los que él denomina "saberes construidos en mí" por ser elaboraciones a las que ha llegado después de un ejercicio "praxeológico, es decir, que está en el vaivén de la práctica y la teoría, mediados por la reflexión permanente como profesional" de otro lado, 
escapando de las citas de autores a las que considera la institucionalización de la academia que terminan por alejar los reales objetivos de la investigación y entronizando la teoría memorizada "prestada" y no encarnada "aplicada".

Los diálogos interepistémicos que Juliao propone en esta obra, se presentan como fractales, como nuevos sistemas de relaciones que permiten la recursividad de las elaboraciones a las que se ha llegado durante más de 20 años de trabajo que Ileva UNIMINUTO aportando a la transformación social, no sólo de su contexto inmediato, sino de Colombia y del mundo, desde la promoción de profesionales éticamente responsables y comprometidos con este proyecto, que supera la institucionalidad, convirtiéndose en un nicho vital, en un nido desde donde se planean, pero no determinan las realidades de los seres vivos.

La dialógica que nos comparte Juliao, oscila entre los aportes que brindan las prácticas, las experiencias y las teorías, las grandes elaboraciones conceptuales, que son tan válidas las primeras como las segundas. Sin separar, pero sí reconociendo los elementos constitutivos de esta propuesta, es importante traer a este escenario el entendido que Juliao acopla a su elaboración, el concepto de "social" en el que es vital religarlo y reconocerlo desde su origen, es decir, desde cuando era asumido como "el espacio de la comunidad en donde se concretan maneras de promover una educación para la vida pública" P.19. La construcción de una educación ligada a lo social, vinculada al mundo de la vida y que en palabras de Assmann, una educación a lo largo de la vida, que no busque las réplicas de los modelos, sino que se manifieste la creatividad, la transformación de los sujetos que se dan cita en el gran teatro de la vida, en un teatro que se diversifica cada vez más cuando reconocemos las diversidades, las diferencias, entre otras.

En este orden de ideas, la compresión del bucle recursivo pedagogía-praxeologíasocioeducación, se dan en la generación de propuestas que posibiliten la existencia de muchos mundos en nuestro mundo, en la inclusión, entendida esta como el reconocimiento de habilidades, capacidades, necesidades y posibilidades que se presentan como condiciones de un ser vivo que se encuentra sometido a la inevitable transmutación de las realidades, a las que se enfrenta en lo cotidiano. En Colombia, tenemos una gran cantidad de realidades que se presentan ante nuestros sentidos, que en el día a día se manifiestan impermanentes, inestables y paradójicamente, queremos una educación fija, estática, determinada a las instituciones, poco comprometida con las grandes transformaciones a las que está invitada a participar y que tiene grandes deudas, grandes compromisos por tomar, desafíos por asumir. Una Colombia que presenta policromías, enormes brechas económicas, políticas, sociales, entre otras. Así mismo, los niños, niñas, jóvenes y adultos se vuelven habitantes nómadas, sin territorios, por fuera de las instituciones sociales. Como lo cita Juliao p. 48, de Restrepo, 1999, p. 10 "La tesis básica que se concluye para definir la vida, poniendo a prueba una pedagogía novedosa para construir las identidades éticas que queremos, se trata de innovar una metáfora de la tierra que nos identifique" 
En términos sociales, una tierra que nos identifique, nos lleva al replanteamiento de las resistencias, es decir, a los procesos de emancipación y transformación de los sujetos, a ese dejar de ser nómada en su propia casa. Una educación que permita el empoderamiento de las clases sociales y que las posicione en escenarios políticos, donde se toman decisiones, apoyándose en los procesos pedagógicos que luchan en contra de los paradigmas dominantes que pretenden mantener las estáticas piramidales de las clasificaciones dicotómicas entre ricos y pobres.

Una educación que se promueva desde estas nuevas fronteras, desde estos entendidos, es la invitación que Carlos Germán Juliao nos hace para transformar no sólo el sistema social, educativo, las pedagogías, sino las instituciones, que transmuten hacia organizaciones aprendientes mucho más vitales, que se flexibilicen pensando en las sociedades y en los seres vivos que habitan y cohabitan en las convergencias y divergencias de estas realidades educativas. 